Gut, 1966, 7, 128.

\title{
Appearances of the jejunal mucosa in acute tropical sprue in Singapore ${ }^{1}$
}

\author{
N. W. J. ENGLAND ${ }^{2}$ and W. O'BRIEN ${ }^{3}$ \\ From the British Military Hospital, Singapore
}

EDITORIAL SYNOPSIS A positive correlation has been found between the jejunal mucosal patterns and histological change and the severity of the malabsorption. Examination of the jejunal mucosa by biopsy is essential for diagnosis and in assessing the response to treatment of patients with malabsorption in the tropics.

In this paper we describe the appearances under the dissecting microscope and the histological appearances of jejunal biopsies taken from 36 European patients with tropical sprue who had been resident in Malaysia for a period not greater than three years. The material is therefore confined to acute tropical sprue. One of the objects of the study was to compare these results with those reported from other sprue areas, such as Puerto Rico (Sheehy, Baggs, Perez-Santiago, and Floch, 1962a) and India (Baker, Ignatius, Mathan, Vaish, and Chacko, 1962). In addition the macroscopical appearances of the jejunal mucosa are correlated with the histological abnormalities, which have been assessed by careful measurements of sections of villi, leaves, and convolutions, and these changes are also correlated with the severity of the malabsorption as measured by the faecal fat excretion and urinary excretion of xylose. The effect of treatment is reported. One of the earliest references to the pathological change in the small intestine in tropical sprue was that of Manson (187980 ) who attributed the symptoms to a remitting inflammation of the mucous membrane of the alimentary canal. Van der Burg (1880) referred to a chronic catarrh of the gastro-intestinal tract with atrophy of the mucous membrane. A more detailed description was given by Bahr, who as early as 1915,

${ }^{1}$ The participants in the Wellcome Trust study on tropical megaloblastic anaemia, of which study this work is part, are as follows: Chairman, Professor J. V. Dacie, Scientific Secretary, Dr. D. L. Mollin; Secretary, Dr. Peter Williams; Professor S. J. Baker (Vellore); Dr. C. C. Booth (Hammersmith Hospital); Lieutenant-Colonel N. W. J. England (Singapore); Dr. Henry Foy (Nairobi); LieutenantColonel W. O'Brien (Singapore).

${ }^{2}$ Present address: R.A.M. College, Millbank, London, S.W.1.

${ }^{3}$ Present address: Queen Alexandra Military Hospital, Millbank, London, S.W.1. demonstrated clearly the appearance of quadrangular and shrunked villi which we now know is so characteristic of tropical sprue. This was confirmed by Koppisch in 1947 (quoted by Suárez, Spies, and Suárez) who performed necropsies on 16 cases of tropical sprue and noted shortening and blunting of villi in half the cases. Interpretation of these reports was made difficult by artefacts produced by autolysis, and it was not until an intestinal biopsy specimen taken at laparotomy and rapidly fixed was examined (Milanes, Leon, and Causa, 1951) that the essential pathological lesion was confirmed. A detailed description of the histological changes in the jejunal mucosa of six cases of tropical sprue obtained by this method was given by Butterworth and PerezSantiago (1958).

The invention of instruments for taking intestinal mucosal biopsies by the peroral route (Shiner, 1956; Crosby and Kugler, 1957; and Brandborg, Rubin, and Quinton, 1959) was a stimulus to the investigation of intestinal malabsorption by this method. The histopathological changes in different types of malabsorption were described in detail by Shiner and Doniach (1959) who found partial villous atrophy in two patients with tropical sprue. They also demonstrated recovery of the jejunal mucosa following treatment. Butterworth, Smith, and Perez-Santiago (1959) emphasized the less severe histological changes in sprue compared with the subtotal villous atrophy usually found in idiopathic steatorrhoea and coeliac disease (Shiner and Doniach, 1959; Fone, Meynell, Harris, Cook, Brewer, and Cox, 1960; and Girdwood, Delamore, and Williams, 1961). Unfortunately in many of the earlier studies little attention was given to the 
orientation of the specimens and Rubin, Brandborg, Phelps, and Taylor (1960) stated that a normal mucosa sectioned tangentially may resemble the appearance of sprue. These authors were also first to draw attention to the striking changes which occur in the gross appearance of the mucosal surface of the small intestine.

Detailed studies of the mucosal patterns seen under the dissecting microscope were made by Holmes, Hourihane, and Booth (1961a and 1961b) and ten Thije (1963). A convoluted mucosal pattern corresponded to partial villous atrophy and a flat pavement pattern to subtotal villous atrophy. Booth (1962) has stressed the value of examining the mucosal biopsy under the dissecting microscope. In idiopathic steatorrhoea the mucosa frequently has a flat pavement pattern (Hourihane, 1963), while in chronic tropical sprue the mucosal pattern is usually either one of leaves or convolutions (Booth, Stewart, Holmes, and Blackenbury, 1962; Klipstein, 1964). Baker, Ignatius, Mathan, Vaish, and Chacko (1962) have never seen a flat mucosa in tropical sprue in Indians, and Sheehy, Perez-Santiago, and Floch (1962b) reported only two cases with a flat mucosa in a series of 46 Puerto Rican patients.

\section{METHODS}

The biopsies were taken from the upper two and a half feet of the jejunum using a Crosby capsule (Crosby and Kugler, 1957). the site of biopsy being confirmed radiologically. The biopsy specimen was rapidly removed from the capsule and after gently stretching on blotting paper it was immediately immersed in $10 \%$ buffered formol saline. After examination under the dissecting microscope, as described by Holmes et al. (1961a), the biopsy was photographed. Following fixation it was cut in two planes at right angles and serial histological sections were prepared from conventional paraffin blocks and stained by haematoxylin and eosin and also by the periodicacid-Schiff reagent. Care was taken during embedding to orientate the specimen correctly with the long axes of the villi parallel to the cutting surface. Obliquely cut sections, as shown by incomplete villi, crypts in cross section, and absence of muscularis mucosae, were rejected and new ones prepared.

The serial section showing the tallest and most slender villi was selected from each biopsy and measurements were made of the total mucosal thickness and the height and width of 10 villi using a calibrated micrometer eye piece at a magnification of 100 . In estimating the width of villi two measurements were taken; one was the greatest external width and the other was the internal width between the basement membranes of the columnar cells at the trough of the saw-tooth. The internal width was measured because it had been observed that one of the early changes in tropical sprue was swelling of the villi with the loss of the saw-tooth pattern, resulting in increase in the internal width with less change in the external measurements. The height of the columnar epithelial cells was measured at the tips of 10 villi using a micrometer eye-piece at a magnification of 400 . The set of measurements for each biopsy was repeated, frequently by a second observer, and the means were calculated.

The intensity of the cellular infiltration of the lamina propria was graded as mild $(+)$, moderate $(++)$, or severe $(+++)$, and an estimate was made of the relative frequency of the types of call present. The columnar epithelium was examined for continuity, regularity, and polarity of the nuclei, vacuolation of the cytoplasm, and cellular infiltration.

Classification OF JEJUNAL MUCOSAL PATTERNS The appearances of the intestinal mucosa under the dissecting microscope were classified on the lines suggested by Holmes et al. (1961a). Biopsics have been arranged into the following groups: 'predominantly villi', 'villi and leaves', 'predominantly leaves', 'thickened leaves', 'convolutions', and 'flat pavement'. Classification was sometimes made difficult by a varied pattern seen in the same biopsy. For example, Fig. 1a and 1b show respec:ively a predominantly villous pattern and a predominantly leaf pattern occurring in different areas of the same biopsy of a control subject.

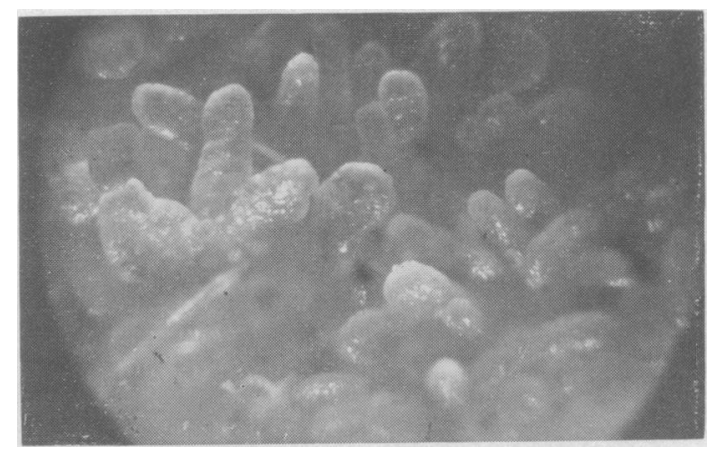

FIG. 1a. Jejunal biopsy from European control with an area of mucosa composed of tall villi. $\times 50$

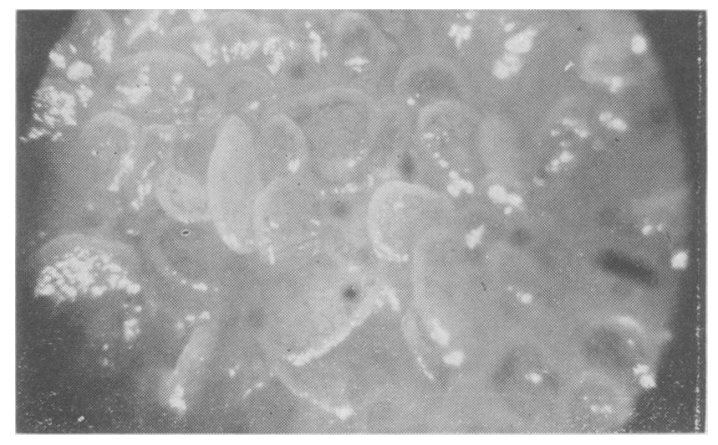

FIG. 1b. Another area from tine biopsy shown in Fig. Ia with an area of leaves. $\times 50$ 


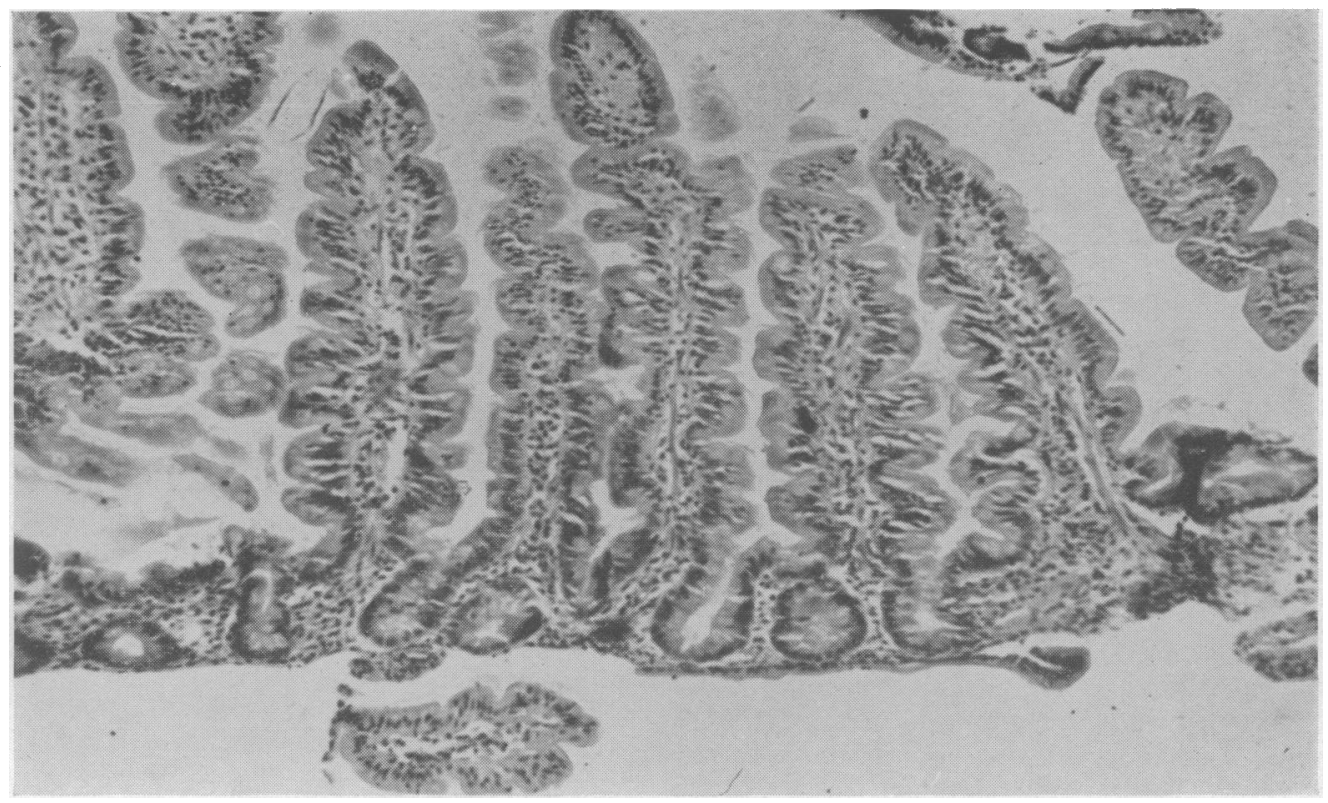

FIG. 1c. Histological section of same biopsy as shown in Figs. 1a and 1b. $\times 120$

BIOCHEMICAL METHODS Faecal fats were estimated by the method of Van de Kamer, ten B. Huinink, and Weyers (1949) and the xylose excretion test by the method of Santini, Sheehy, and Martinez-de Jesus (1961).

PATIENTS STUDIED Biopsies were performed on 14 European patients without evidence of malabsorption as shown by normal faecal fat and d-xylose excretion. Although these were used as controls for standards of comparison they were not true controls, because the majority had mild gastrointestinal symptoms and six had evidence of folate depletion with reduced serum folate levels, but without evidence of megaloblastic anaemia. Eight Asian patients with folate depletion and varying degrees of megaloblastic anaemia but without evidence of malabsorption, as shown by faecal fat and d-xylose excretion tests, were submitted to biopsy. The results of biopsies on 36 patients with acute tropical sprue were studied and repeat biopsies were performed on 16 after treatment with folic acid. The selection of these patients with more complete clinical details and the therapeutic regime have been described elsewhere (O'Brien and England, 1964).

\section{RESULTS}

CONTROL SUBJECTS

EUROPEAN PATIENTS Table I shows the mucosal patterns of the jejunal biopsies seen under the dissecting microscope in 14 European patients who had no evidence of malabsorption. Of the 14 patients, 13 had a villous and leaf pattern and one had a predominantly leaf pattern. These structures were tall and slender and had a delicate vascular pattern visible through the transparent epithelium. The mean dimensions of these mucosae are shown in Table II.

In all except two biopsies the cellular infiltration of the lamina propria was mild $(+)$. The cells were composed predominantly of lymphocytes but a few plasma cells were also present. Eosinophils were rarely seen. The columnar epithelium was tall and regular and in some cells there was basal vacuolation.

ASIAN PATIENTS WITHOUT STEATORRHOEA In contrast to the European controls these biopsies from

TABLE I

COMPARISON OF MUCOSAL PATTERNS OF JEJUNAL BIOPSIES IN PATIENTS WITHOUT MALABSORPTION AND IN THOSE WITH TROPICAL SPRUE

\begin{tabular}{lcccc} 
& No. of Patients & Villi and Leaves & Leaves & Thickened Leaves Convolutions \\
\hline Europeans without malabsorption & 14 & $13(93 \%)$ & $1(7 \%)$ & 0 \\
Asians without malabsorption & 10 & $1(10 \%)$ & $6(60 \%)$ & 0 \\
Tropical sprue & 36 & $5(14 \%)$ & $5(14 \%)$ & $14(39 \%)$
\end{tabular}


TABLE II

MEAN MEASUREMENT OF THE MUCOSAE OF EUROPEAN AND ASIAN CONTROLS AND PATIENTS WITH TROPICAL SPRUE ${ }^{1}$

\begin{tabular}{|c|c|c|c|c|c|}
\hline \multirow{2}{*}{$\begin{array}{l}\text { No. of } \\
\text { Patients }\end{array}$} & \multirow{2}{*}{$\begin{array}{l}\text { Total Thickness } \\
(\mu)\end{array}$} & \multirow{2}{*}{$\begin{array}{l}\text { Villous Height } \\
(\mu)\end{array}$} & \multirow{2}{*}{$\begin{array}{l}\text { Subvillous } \\
\text { Thickness }(\mu)\end{array}$} & Villous $W$ & \multirow{2}{*}{$\begin{array}{l}\text { Columnar Cell } \\
\text { Height }(\mu)\end{array}$} \\
\hline & & & & External & \\
\hline
\end{tabular}

\section{Controls}

Europeans

Asians

14
10

$\begin{array}{llllll}555 & 28(426-778) & 446 \pm 23(345-616) & 109 \pm 6(75-162) & 124 \pm 3(98-135) & 42 \pm 2(36-56)\end{array}$

$489 \pm 14(438-560) \quad 363 \pm 13(312-422) \quad 126 \pm 8(91-171) \quad 145 \pm 8(115-185) \quad 55 \pm 5(30-83)$

$30 \pm 0 \cdot 8(26-34)$

Tropical sprue

Villi and leaves

Thick leaves

$493 \pm 26(407-665) \quad 365 \pm 18(300-453) \quad 128 \pm 18(35-230) 132 \pm 8(98-195) \quad 56 \pm 7(30-102) \quad 27 \pm 0 \cdot 6(25-30)$

Convolutions

$464 \pm 19(348-591) \quad 315 \pm 17(224-383) \quad 149 \pm 11(97-259) 145 \pm 4(122-184) 68 \pm 5(42-101) \quad 27 \pm 0 \cdot 8(24-33)$

$367 \pm 18(280-500) 248 \pm 12(176-289) \quad 119 \pm 10(72-188) 146 \pm 7(115-184) 82 \pm 5(52-113) \quad 25 \pm 0 \cdot 7(20-33)$

${ }^{1}$ The figures given are the mean, the standard error of the mean, and the range.

Chinese and Indians had a leaf (Fig. 2a) or convoluted pattern with the exception of one which was composed of villi and leaves (Table I). This patient differed from the others in being a young Gurkha soldier. In two of the biopsies classified as leaves, some of the leaves were elongated and had fused to form ridges without reaching the stage of convolutions.

The mean dimensions of the mucosae of this group are shown in Table II. In Fig. 3 they are compared diagrammatically with European controls and patients with tropical sprue. The measurements of the Asian patients were compared statistically with those of the European controls. The mean total mucosal thickness was reduced but this was not statistically significant. There was a significant reduction in the mean villous height $(\mathrm{P}<0.05)$ and increase in the villous external width $(P<0.02)$ and internal width $(\mathrm{P}<0.05)$. Thus in transverse section the villi, leaves, and convolutions of the Asian patients were on the average shorter and broader than of the European controls. In some there was an increase in the subvillous thickness associated with mild glandular hyperplasia (Fig. 2b). The histological appearances ranged from normal to partial villous atrophy and were similar to those in Europeans with mild tropical sprue. Further evidence of abnormality was shown by an increase in the intensity of the cellular infiltration $(++)$ with plasma cells in five of the biopsies. Increased eosinophil infiltration was also seen.

TROPICAL SPRUE The mucosal pattern of the jejunal biopsies from 36 patients with tropical sprue are summarized in Table I. Ten were composed of either villi and leaves or predominantly leaves, and, although the only difference from normal as seen under the dissecting microscope, was an increased proportion of leaves, measurements of transverse sections of villi and leaves in histological sections revealed significant changes compared with European control subjects (Table II and Fig. 3). Thus there

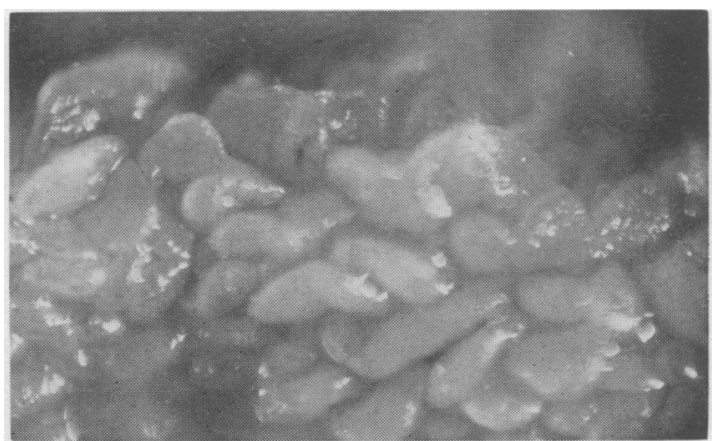

FIG. 2a. Asian control without malabsorption showing jejunal mucosa composed of thickened leaves. $\times 50$



FIG. 2b. Histological section from same biopsy as shown in Fig. 2a. Note the tall transverse sections of leaves which appear as villi, but with increased width compared with European control in Fig. 1c. $\times 120$ 


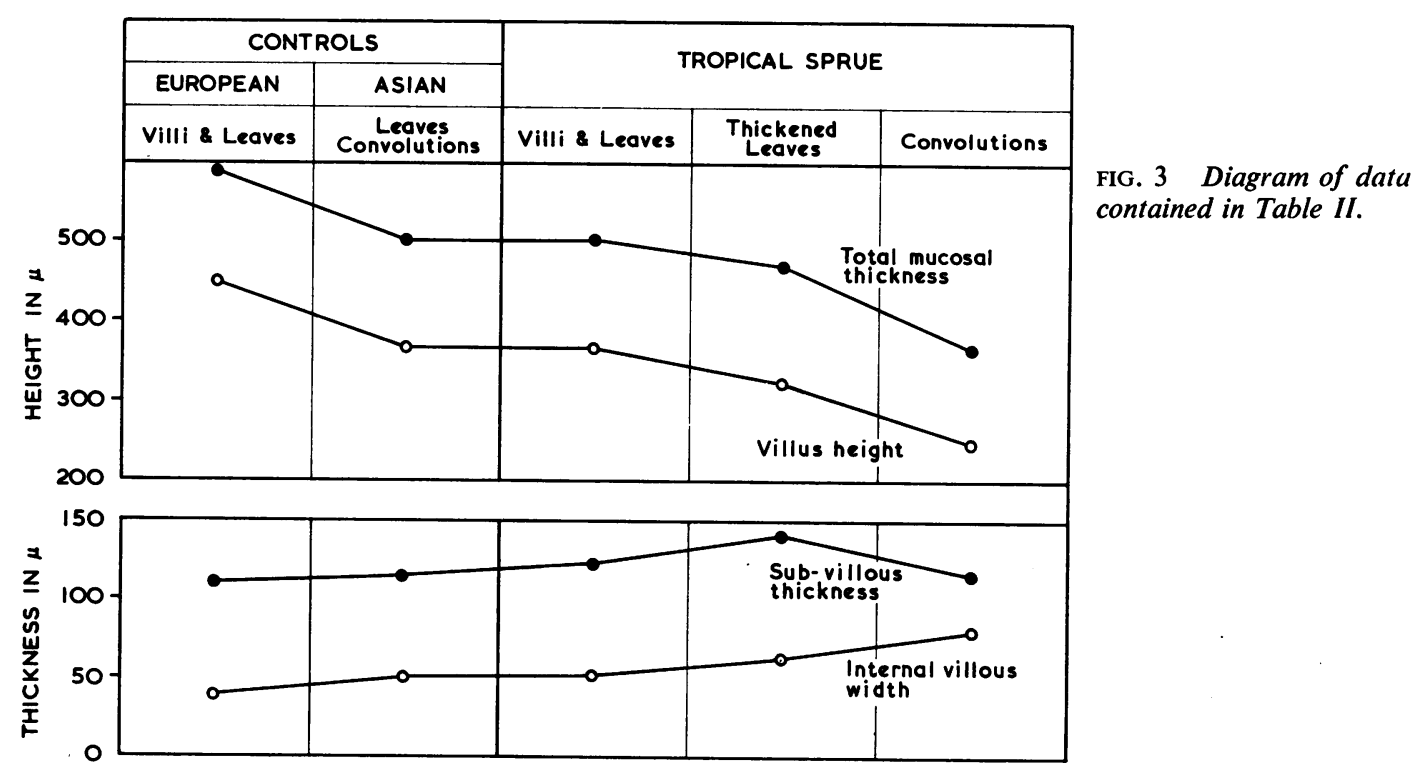

was significant reduction in the mean villous height $(P<0.02)$, increase in internal villous width $(\mathrm{P}<0.05)$, and reduction in columnar cell height $(P<0.05)$. The total mucosal thickness was not significantly reduced because of the glandular hyperplasia causing an increase in the subvillous thickness. These changes were apparent in the overall impression of the sections, which were classified as showing either minor abnormality or mild partial villous atrophy. In all except two biopsies, the cellular infiltration was graded as moderate $(++)$ or severe $(+++)$ with plasma cells being predominant. In the majority, eosinophils were also prominent. Associated with reduction in the columnar cell height there was irregularity in the nuclei and slight infiltration of the epithelium by lymphocytes. These biopsies, which were taken from mild cases of sprue, showed the earliest histological changes consisting of increased cellular infiltration and shortening and swelling of villi with loss of the saw-tooth pattern of the borders.

Biopsies from a further 14 patients showed a thickened leaf pattern. Under the dissecting microscope the appearances were those of turgid leaves of reduced height lying packed together (Fig. 5a). In some areas there were ridges formed by the fusion of adjacent leaves which sometimes resulted in bridge formations. The mucosa was more opaque, resulting in the blood vessels being indistinct and mucus was usually present in large amounts. The mean histological measurements of these biopsies are summarized in Table II and shown diagrammatically in Figure 3. The mean villous height was considerably reduced but the total mucosal thickness was less reduced because the subvillous thickness was increased significantly above that of the normal mean of $109 \mu$ as a result of glandular hyperplasia $(P<0.001)$ (Fig. 5b). The mean villous external and internal widths were increased. As in the previous group the columnar cell height was reduced. Inflammatory cellular infiltration was markedly increased and in the majority there was an increase in the eosinophils in addition to plasma cells.

In 12 biopsies a convoluted pattern was seen apparently formed by the fusion of ridges to produce a complex interlacing network or honeycomb (Figs. 7a and 8a). These convolutions appeared swollen and flattened and the vascular pattern was irregular and distorted. The histologicalmeasurements of this group are summarized in Table II and Figure 3. The reduction of mean total mucosal thickness and villous height was most severe in this group. In some biopsies the severe reduction in villous height was unassociated with increase in the subvillous thickness and this resulted in mucosal atrophy (Fig. 8b). In contrast to the previous group, the mean subvillous thickness was not significantly greater than normal. The mean columnar cell height was reduced and in most biopsies the lamina propria was heavily infiltrated by plasma cells, lymphocytes, and eosinophils. These cells also infiltrated the columnar cells.

RELATIONSHIP BETWEEN SEYERITY OF MALABSORPTION AND MUCOSAL PATTERNS OF THE JEJUNUM AND DEGREE OF 'VILlous ATROPHY' Patients with sprue 
TABLE III

SIGNIFICANCE OF THE DIFFERENCE OF THE MEAN FAECAL FAT AND D. XYLOSE EXCRETION IN PATIENTS WITH TROPICAL SPRUE WITH DIFFERENT MUCOSAL PATTERNS ${ }^{1}$

\begin{tabular}{|c|c|c|c|c|}
\hline Mucosal Pattern & Faecal Fats (g./day) & $\begin{array}{l}\text { Statistical Significance of } \\
\text { Difference of Means }\end{array}$ & $\begin{array}{l}\text { D. xylose Excretion } \\
(\% \text { excreted })\end{array}$ & $\begin{array}{l}\text { Statistical Significance of } \\
\text { Difference of Means }\end{array}$ \\
\hline Villi and leaves & $12 \cdot 6 \pm 1 \cdot 7(6 \cdot 0-21 \cdot 1)$ & $p<0.05$ & $14 \cdot 7 \pm 3 \cdot 4(24 \cdot 1-8 \cdot 0)$ & Not significant \\
\hline $\begin{array}{l}\text { Thick leaves } \\
\text { Convoluted }\end{array}$ & $\begin{array}{l}17.9 \pm 2 \cdot 3(8 \cdot 8-34 \cdot 9) \\
19 \cdot 7 \pm 2 \cdot 8(6 \cdot 6-34 \cdot 8)\end{array}$ & Not significant & $\begin{array}{c}11 \cdot 3 \pm 1.4(17 \cdot 9-4 \cdot 0) \\
6.6 \pm 0.6(9 \cdot 7-3 \cdot 2)\end{array}$ & $p<0.01$ \\
\hline
\end{tabular}

${ }^{1}$ The figures given are the mean, the standard error, of the mean, and the range.

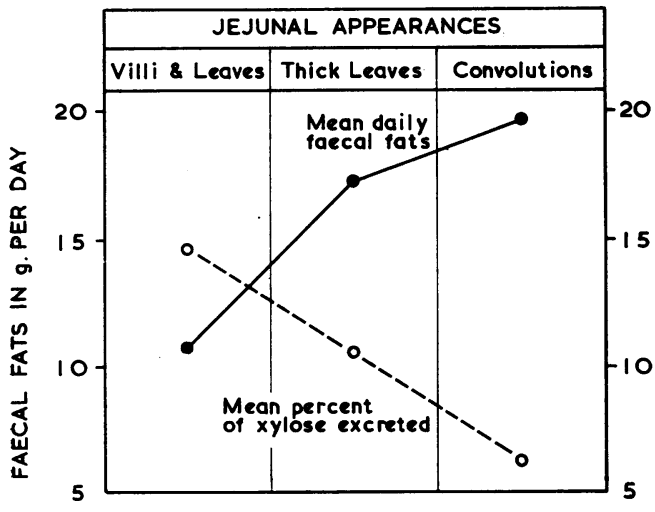

FIG. 4

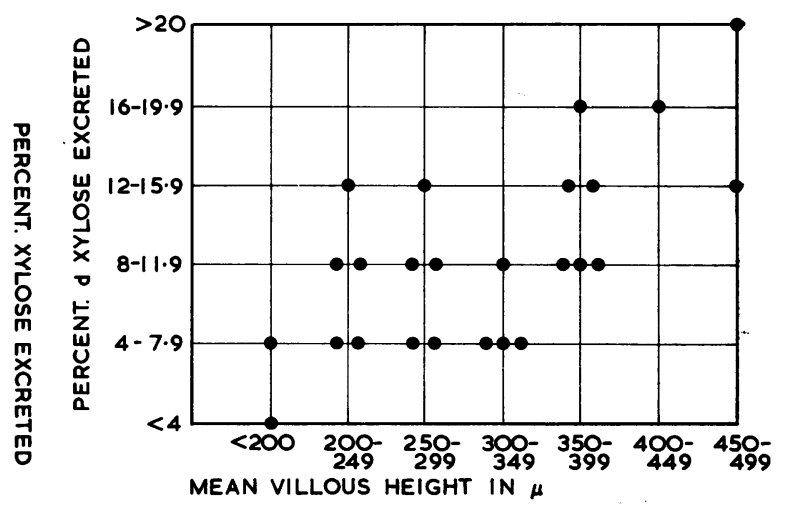

FIG. 5

FIGS. 4 and 5. Diagrammatic representation of data in Table III and mean villous height in 25 patients (Fig. 8) for whom findings were available.

were arranged into three groups according to the pattern of the jejunal mucosa, and the mean daily faecal fat excretion and mean urinary xylose excretion were calculated for each group. The results are summarized in Table III and shown diagrammatically in Figure 4. Thus patients with a thickened leaf pattern had a significantly greater steatorrhoea than those with a villous and leaf mucosal pattern, and the mean xylose excretion of those with a convoluted pattern was significantly less than those with thickened leaves.

The xylose excretion of 25 patients for whom we had the data was plotted against the mean villous height in the scatter diagram (Fig. 5). This shows that there was moderate correlation between the severity of the malabsorption and the degree of villous atrophy (correlation coefficient $0 \cdot 67$ ). We found no correlation, however, between the faecal fat excretion and the mean villous height (correlation coefficient 0.32 ).

EFFECTS OF TREATMENT WITH FOLIC ACID ON THE JEJUNAL MUCOSA The haematological responses of patients with tropical sprue to parenteral folic acid therapy has been described elsewhere (O'Brien and
England, 1964). The effect of folic acid on the jejunal mucosa of these patients is shown in Table IV. Repeat biopsies were performed in 16 patients after treatment and although in many of these patients several biopsies were taken at intervals, only the results of the final biopsies are shown.

Of eight biopsies with a thickened leaf pattern (Table IV), seven reverted to villi and leaves over a period from two to five months. This rapid change in mucosal pattern was associated with improvement in the histological architecture as shown by increase in the mean villous height and reduction in the transverse internal width of villi and leaves $(P<0.05)$ compared with the mean values before treatment. The glandular hyperplasia, shown by increase in the mean subvillous thickness, disappeared following therapy.

Improvement was also observed in eight biopsies with a convoluted pattern (Table IV). Four remained convoluted (Fig. 7c and 8c) over a period of from two to nine months, but the other four, when followed for a longer period (from 10 to 18 months) developed a villous and leaf pattern (Fig. 8e). In several of the biopsies taken from cases of more severe tropical sprue, the convolutions were ill 


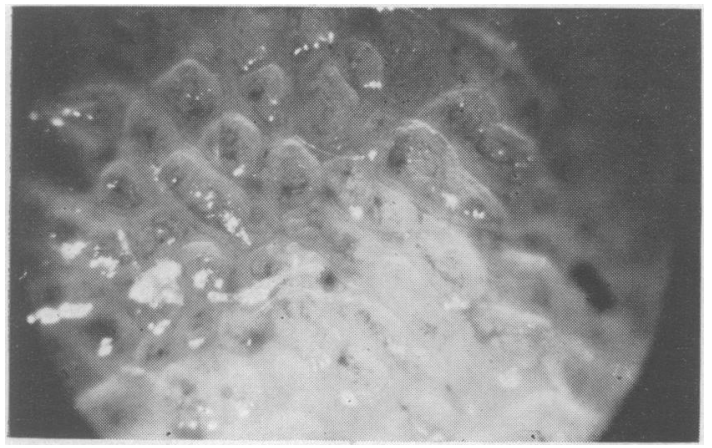

FIG. 6a. A thickened leaf mucosal pattern from a case of moderate tropical sprue. $\times 50$

FIG. 6b. Histological section from a mucosa composed of thickened leaves. $\times 120$

FIG. 6a.

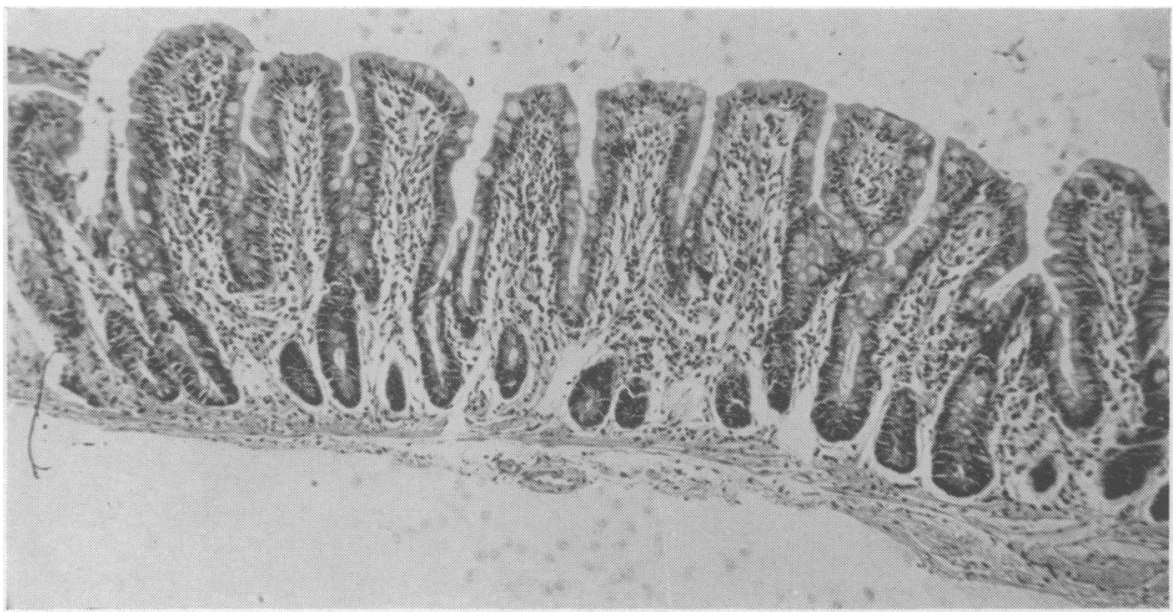

FIG. $6 \mathrm{~b}$.

defined, flattened, swollen, and covered by tenacious mucus (Fig. 7a and 8a). Although during the early period following treatment these convolutions persisted, they became taller, less turgid, and more clearly outlined (Fig. 7c). Later there was decrease in the complexity of the convolution (Fig. 8c) and a return of leaves and villi (Fig. 8e). There was early improvement in the histological architecture (Figs. $7 \mathrm{~d}$ and 8d) following treatment, at a time when the mucosae remained convoluted. As shown in Table IV there was a significant increase in the mean height $(\mathrm{P}<0.01)$ and decrease in the mean transverse internal width $(\mathrm{P}<0.01)$ of the convolutions compared with the mean values before treatment. There was an even greater histological improvement (Fig. 8f) in those biopsies which had recovered a leaf and villous pattern with a significant increase in the mean villous height $(P<0.01)$ and reduction in the mean internal width $(P<0.01)$ compared with the pre-treatment measurements. Although in the majority of the biopsies the mean transverse width of the villi, leaves, or convolutions returned to within the range of the control biopsies, the recovery of the height of these structures was slower and it had returned to within the range of the controls in only $56 \%$ of the final repeat biopsies. The mean columnar cell height was higher after treatment but the differences compared with the pre-treatment heights were not significant.

Following treatment the glandular hyperplasia disappeared as shown by decrease in the mean subvillous thickness (Table V) and in those biopsies with a tendency towards glandular hypoplasia (mean subvillous thickness, $79 \mu$ Table V), the mean subvillous thickness returned to within the normal range after treatment. There was no correlation between the rate of regeneration of the villi and the degree of glandular hyperplasia and it was frequently observed that the hyperplasia disappeared during the initial phases of recovery while the villi were still stunted.

In all cases the intensity of the cellular infiltration 


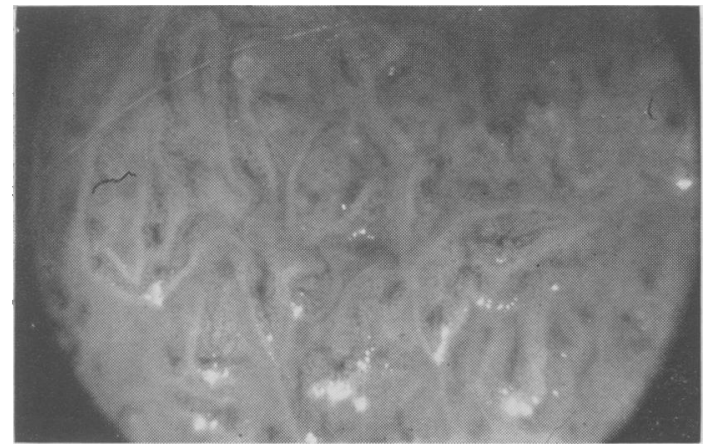

FIG. 7a. Jejunal mucosa showing a convoluted pattern from a case of moderate tropical sprue. $\times 50$

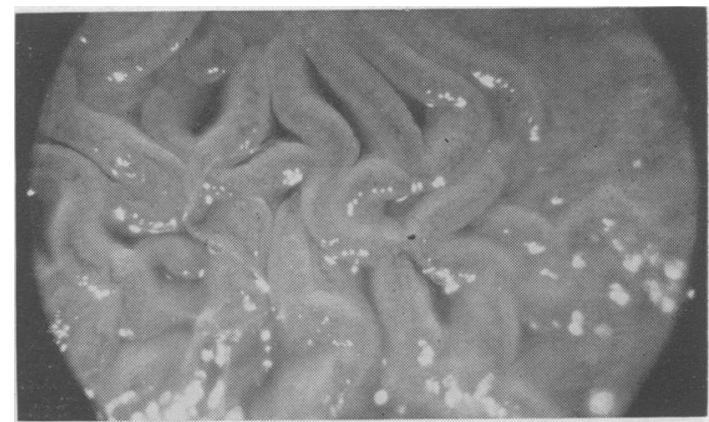

FIG. 7c. Biopsy from the same patient as in Fig. $7 a$ two months after treatment showing persistence of convolutions. $\times 50$

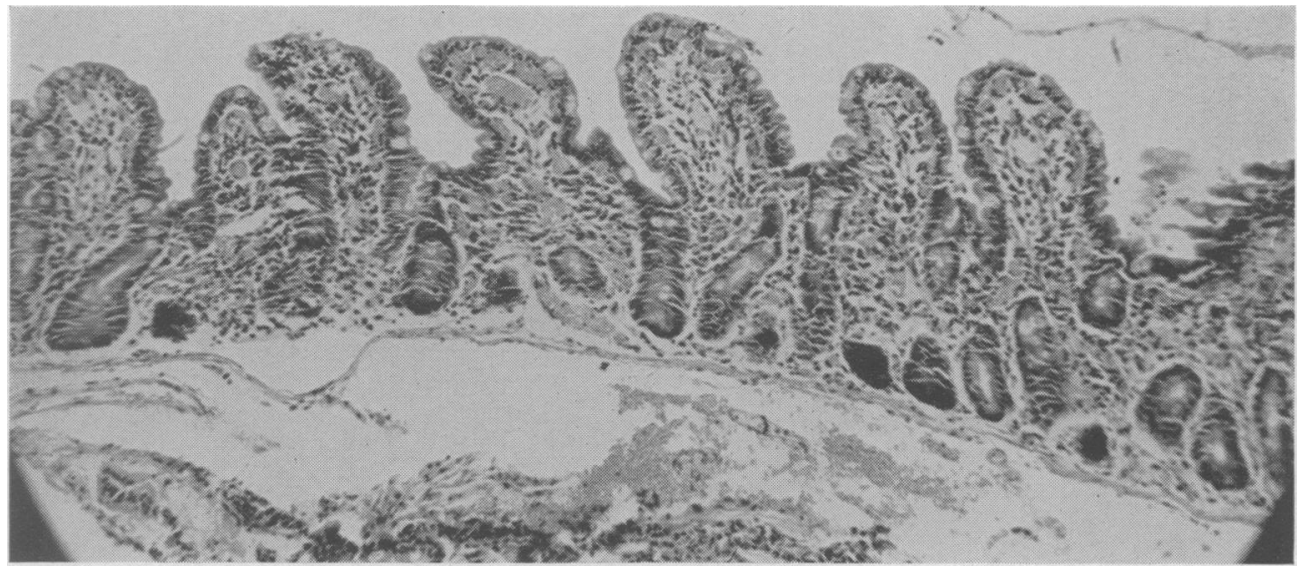

FIG. 7b. Histological section from same biopsy as Fig. 7a. This shows transverse sections of swollen convolutions with increased cellular infiltration of the lamina propria. The subvillous zone is increased as a result of glandular hyperplasia. $\times 120$

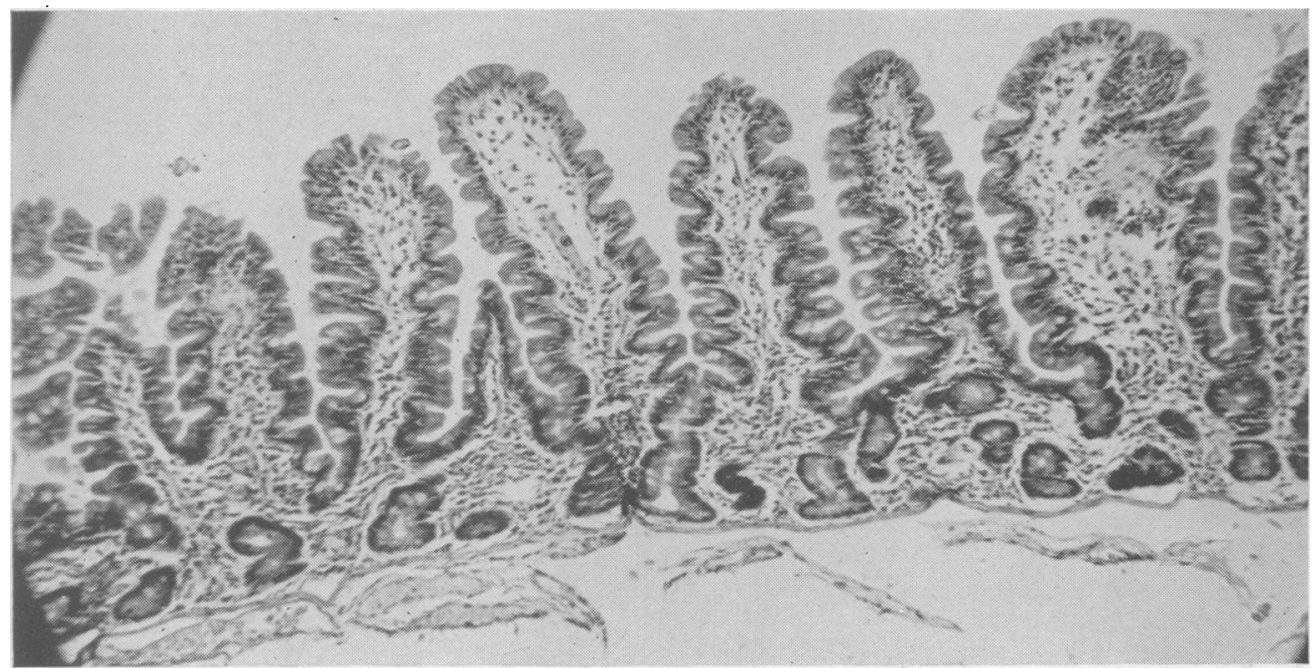

FIG. 7d. Histological section from same biopsy as Fig. 7c. This appears histologically to be almost normal. $\times 120$ 


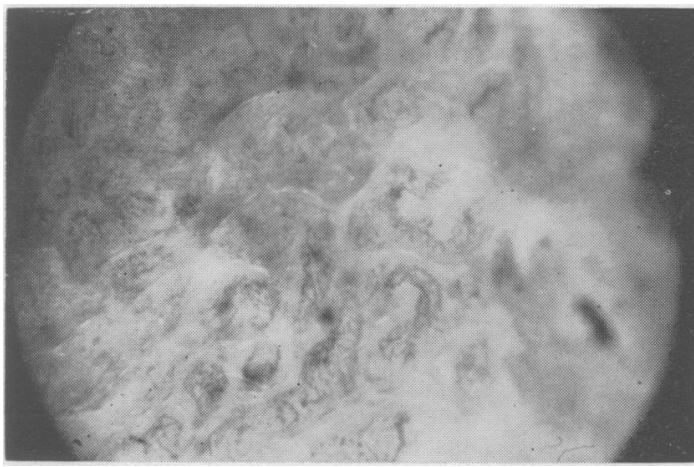

FIG. 8a. This shows the mucosal pattern of a biopsy for a case of severe tropical sprue. The convolutions are flattened and turgid. $\times 50$

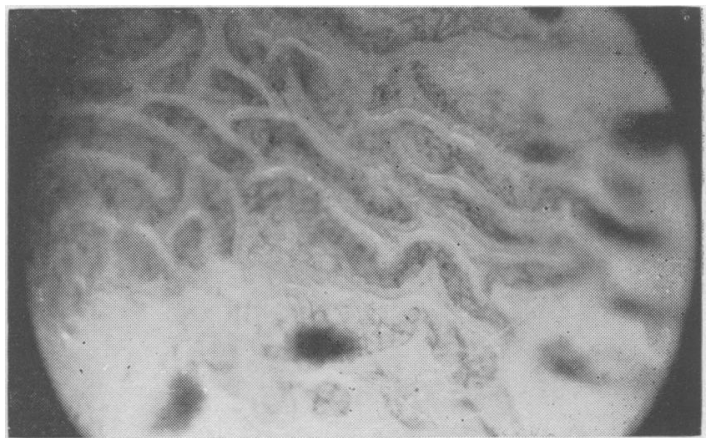

FIG. 8c. This shows the mucosal pattern of a biopsy from the same patient as in Fig. 8a. The pattern is now one of ridges and convolutions which are taller and more slender than in the initial biopsy. $\times 50$

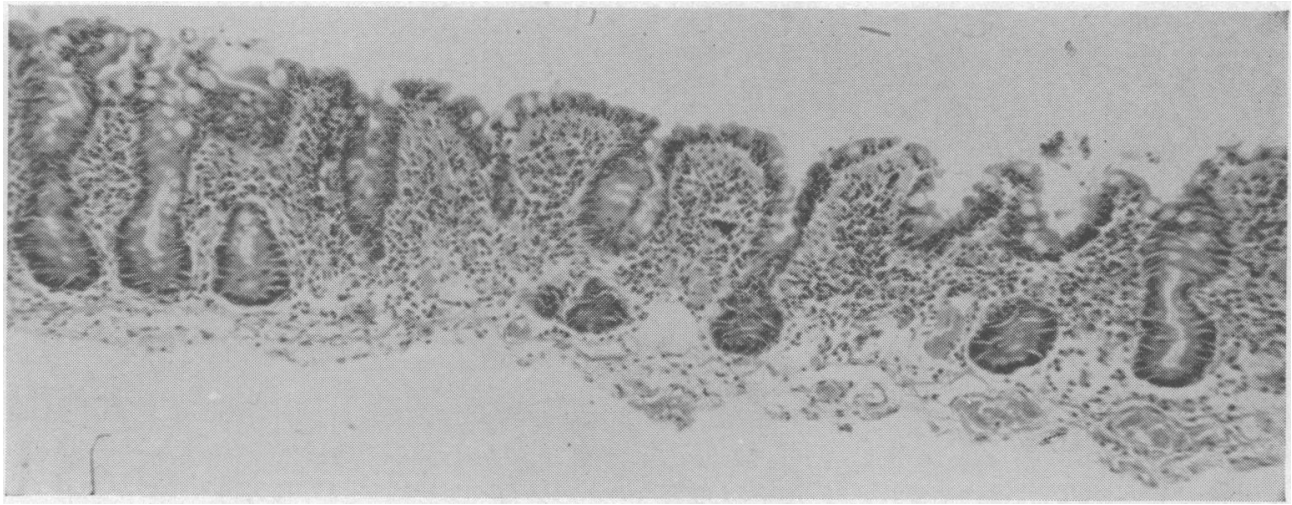

FIG. 8b. Histological section of same biopsy as Fig. 8a. There is severe partial villous atrophy with thinning of the mucosa. $\times 120$



FIG. 8d. Histological section from same biopsy as Fig. 8 c. There is marked improvement. $\times 120$ 


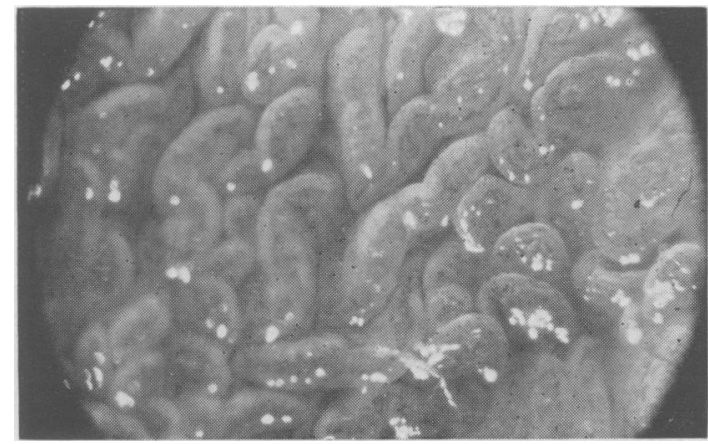

FIG. 8e. Repeat biopsy from same case as shown in Fig. 8a, nine months later. Note the return of leaves, although convolutions are still present. $\times 50$

FIG. 8f. Histological section from same case as Fig. 8e. This shows only minor histological abnormality with reduction in the 'villous' height. $\times 120$

FIG. $8 \mathrm{e}$.

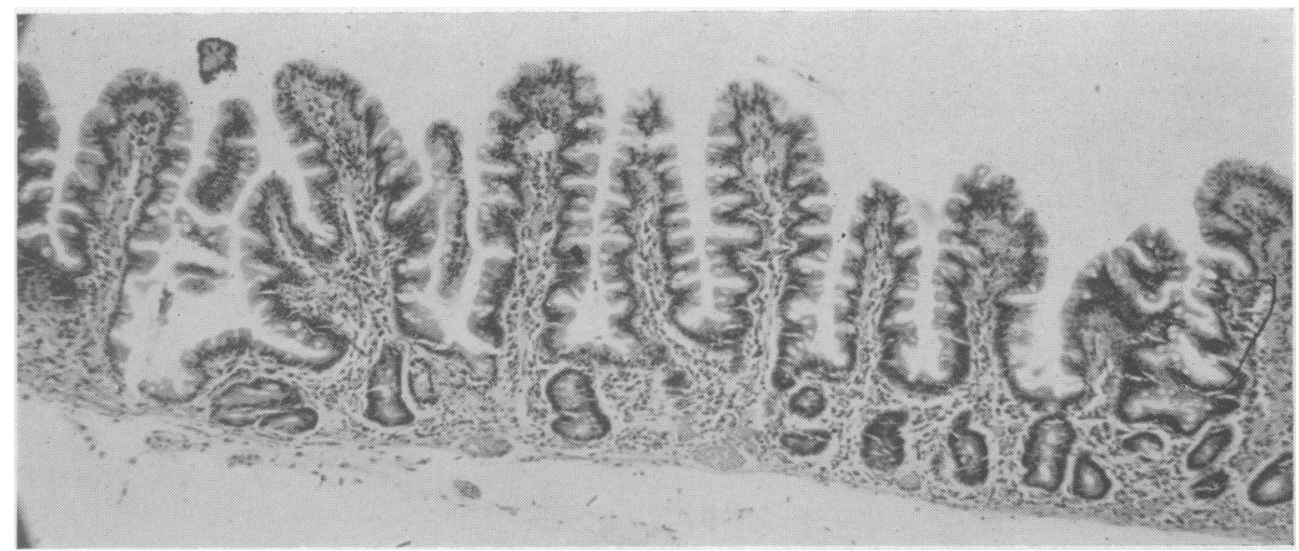

FIG. $8 f$.

TABLE IV

RESULTS OF TREATMENT ON BIOPSIES HAVING INITIAL THICKENED LEAF AND CONVOLUTED MUCOSAL PATTERNS ${ }^{1}$

\begin{tabular}{|c|c|c|c|c|c|c|c|}
\hline \multirow{2}{*}{$\begin{array}{l}\text { No. of } \\
\text { Patients }\end{array}$} & \multirow{2}{*}{\multicolumn{2}{|c|}{$\begin{array}{l}\text { Mucosal Total Thickness } \\
\text { Pattern }(\mu)\end{array}$}} & \multirow{2}{*}{$\begin{array}{l}\text { Villous Height } \\
(\mu)\end{array}$} & \multirow{2}{*}{$\begin{array}{l}\text { Subvillous } \\
\text { Thickness }(\mu)\end{array}$} & \multicolumn{2}{|l|}{ Villous Width $(\mu)$} & \multirow{2}{*}{$\begin{array}{l}\text { Columnar Cell } \\
\text { Height }(\mu)\end{array}$} \\
\hline & & & & & External & Internal & \\
\hline $\begin{array}{l}8 \\
7 \\
1\end{array}$ & $\begin{array}{l}\text { T.L. } \\
\text { V.L. } \\
\text { Con. }\end{array}$ & $\begin{array}{l}454 \pm 25(361-590) \\
475 \pm 20(412-518) \\
490\end{array}$ & $\begin{array}{l}313 \pm 19(257-383) \\
360 \pm 17(290-417) \\
350\end{array}$ & $\begin{array}{l}141 \pm 15(72-207) \\
115 \pm 9(74-143) \\
140\end{array}$ & $\begin{array}{l}148 \pm 6(122-184) \\
141 \pm 6(119-151) \\
131\end{array}$ & $\begin{array}{l}73 \pm 8(47-101) \\
54 \pm 4(34-64) \\
43\end{array}$ & $\begin{array}{l}27 \pm 1 \cdot 1(24-30) \\
29 \pm 1 \cdot 5(25-36) \\
28\end{array}$ \\
\hline $\begin{array}{l}8 \\
4 \\
4\end{array}$ & $\begin{array}{l}\text { Con. } \\
\text { Con. } \\
\text { V.L. }\end{array}$ & $\begin{array}{r}370 \pm 23(290-500) \\
430 \pm 25(394-502) \\
492 \pm 24(450-519) \\
\text { Con }=\text { convoluted }\end{array}$ & $\begin{array}{r}252 \pm 13(193-306) \\
322 \pm 22(273-380) \\
379 \pm 16(349-415) \\
\text { T.L. }=\text { thick }\end{array}$ & $\begin{array}{l}118 \pm 12(96-194) \\
108 \pm 8(90-123) \\
113 \pm 9(101-131) \\
\text { ened leaves }\end{array}$ & $\begin{array}{l}146 \pm 10(115-168) \\
126 \pm 8(110-146) \\
132 \pm 10(107-158) \\
. \text { L. = villi and leave }\end{array}$ & $\begin{array}{l}82 \pm 8(67-113) \\
41 \pm 4(32-50) \\
43 \pm 4(38-53) \\
\text { es }\end{array}$ & $\begin{array}{l}25 \pm 1 \cdot 6(24-30) \\
29 \pm 1 \cdot 3(27-33) \\
27 \pm 1 \cdot 5(26-29)\end{array}$ \\
\hline
\end{tabular}

TABLE V

of the lamina propria decreased following treatment but in only six of the final repeat biopsies had it returned to normal.

\section{DISCUSSION}

We have shown that in European patients with acute tropical sprue the jejunal mucosal appearance was variable. Mucosal pattern consisting of villi and leaves, thickened leaves, and convolutions have been 
found. Our mildest cases usually had a villous and leaf pattern, and Sheehy, Cohen, and Brodsky (1963) have also described this appearance in cases of tropical sprue. Cases of moderate severity had a thickened leaf pattern and the most severe cases had a convoluted appearance. To assess histological changes more accurately detailed measurements of the histological sections were performed. The range of these measurements in our European control subjects was similar to those of Shiner and Doniach (1959) and Sheehy et al. (1963) but not so wide as that reported by Thurlbeck, Benson, and Dudley (1960). All our biopsies from cases of tropical sprue showed histological abnormality ranging from minor change to severe partial villous atrophy. In those with a leaf or villous pattern the histological change was least severe and in some cases was confined to increased cellular infiltration of the lamina propria, which has also been claimed by Sprinz (1962). Biopsies composed of thickened leaves showed partial villous atrophy, while those having a convoluted pattern usually showed more marked villous atrophy. A flat pavement pattern with subtotal villous atrophy was seen in two patients who suffered from idiopathic steatorrhoea, but unlike Sheehy et al. (1962b) we have not seen these appearances in tropical sprue.

With treatment thickened leaves were rapidly restored to apparently normal leaves, but although the leaves become slender, histological measurements revealed that their mean height was less than normal even at the end of several months. The mucosae with convoluted patterns were more refractory to treatment, although, in those followed for a long enough period, villi and leaves developed within 12 to 18 months. The convolutions present several months after treatment were seen to be less turgid and taller, and these changes were readily seen in the histological sections which showed reduced transverse width and increased height of these structures.

In mild lesions, swelling of the villi was one of the most marked histological features and only in the more advanced lesions was there significant reduction in villous height. That swelling of villi represents oedema is supported by the early reduction of villous width and restoration of the saw-tooth pattern of the villous borders following therapy even in the severely affected mucosae. The increase in villous height was much slower and had not returned to normal even after a year, suggesting that other factors are involved. Butterworth and PerezSantiago (1958) have postulated that disturbance in the intestinal epithelium is the result of either decreased survival or diminished production of the columnar cells of the crypts of Lieberkuhn (Leblond and Stevens, 1948), and Doniach and Shiner (1957) have suggested that the glandular hypertrophy is an attempt to maintain an intact villous epithelium in the face of the threatened life span of the cells. We have observed marked hypertrophy of the glandular layer with increase in the subvillous mucosal thickness in moderate partial villous atrophy, but in more severe lesions this glandular hypertrophy was usually absent, and, with marked reductions in villous height, there was considerable thinning of the mucosa resulting in true mucosal atrophy. This confirms the findings of Swanson and Thomasson (1964). Following treatment the glandular hypertrophy quickly disappeared, suggesting that the rapid epithelial cell turnover had ceased, but it was of interest to note that the glandular hypertrophy disappeared before restoration of villi to normal height. Thus, while agreeing with Holmes et al. (1961b) that the histological section is only two-dimensional and what appears to be 'villi' may in fact be transverse sections through ridges, histological sections do reflect accurately improvement in the height and reduction in the width of leaves and convolutions following therapy. Although longitudinal sections of convolutions or ridges would give the appearance of a 'flat' mucosa, this rarely occurs and can be recognized by examination of another section at right angles to the first. However, following treatment the histological appearance may be misleading because, as we have shown, a convoluted mucosa may be present when the corresponding histological architecture is apparently normal.

We agree with Butterworth et al. (1959) and Sheehy et al. (1962a) that there is a positive correlation between the histological changes and severity of the malabsorption as measured by biochemical tests. We have also found a positive correlation between the jejunal mucosal pattern and the severity of the malabsorption. This is contrary to the experience of Baker et al. (1962) who reported no correlation in Indian patients between villous architecture and the absorption of fat and xylose.

Biopsies from Asian patients without evidence of malabsorption had a high incidence of leaves and convolution which confirms the observation of Baker et al. (1962). In addition there were histological changes varying from minor abnormality to partial villous atrophy. Similar results have been reported by Sprinz, Sribhibhadh, Gangarosa, Benyajati, Kundel, and Halstead (1962) in Thai people but its significance is unknown. It has been suggested that the highly spiced Asian diet might act as an irritant (Mollin, 1962). Baker (1962) considered this unlikely, and our finding of tall villi and leaves in Gurkha patients, who eat a highly spiced diet, would support this view. 
In conclusion we consider that the examination of the jejunal mucosa by biopsy is an essential procedure in the diagnosis and in assessing the response to treatment of patients with malabsorption in the tropics. The examination of the biopsy under the dissecting microscope is a rapid method of making a provisional diagnosis. Detailed measurements of the histological changes have enabled us to correlate these changes statistically with the various mucosal patterns, severity of the malabsorption, and the response to treatment.

\section{SUMMARY}

Compared with European control subjects living in Singapore, Asian patients without evidence of malabsorption had abnormal jejunal mucosal patterns. In European patients with acute tropical sprue the mucosal patterns varied from villi and leaves to thickened leaves and convolutions and corresponded to the histological changes which ranged from minimal findings to those of severe partial villous atrophy. There was some correlation between the mucosal patterns and histological change and the severity of the malabsorption. In those patients with a leaf or thickened leaf pattern there was a rapid return to normal following successful treatment with folic acid, although in those with a convoluted pattern and severe partial villous atrophy, the mucosal recovery was delayed; in the majority the mucosa had returned to normal at the end of 12 to 18 months. The histological improvement preceded changes in the gross appearances.

We would like to thank Dr. D. L. Mollin and Dr. C. C. Booth, of the Postgraduate Medical School of London, for their continuous help and encouragement and we are indebted to Major General M. H. P. Sayers, O.B.E., for his support.

\section{REFERENCES}

Bahr, P. H. (1915). A Report on Researches on Sprue in Ceylon. University Press, Cambridge.

Baker, S.J. (1962). In Intestinal Biopsy (Ciba Foundation Study Group No. 14), edited by G. E. W. Wolstenholme and M. P. Cameron, p. 100.

—, Ignatius, M., Mathan, V. I., Vaish, S. K., and Chacko, C. C. (1962). In Intestinal Biopsy in Tropical Sprue (Ciba Foundation Study Group No. 14), pp. 84-101.

Booth, C. C. (1962). In Intestinal Biopsy (Ciba Foundation Study Group No. 14), pp. 100.

- Stewart, J. S., Holmes, R., and Brackenbury, W. (1962). In Dissecting Microscopic Appearances of Intestinal Mucosa (Ciba Foundation Study Group No. 14, pp. 2-19).

Brandborg, L. L., Rubin, C. E., and Quinton, W. E. (1959). A multipurpose instrument for suction biopsy of the oesophagus, stomach, small bowel and colon. Gastroenterology, 37, 1-16.
Burg, C. L., van der (1880). Indische Spruw. Batavia.

Butterworth, C. E., Jr., and Perez-Santiago, E. (1958). Jejunal biopsies in sprue. Ann. intern. Med., 48, 8-29.

_ Smith, R. B. W., and Perez-Santiago, E. (1959). Pathologic findings in jejunal specimens obtained by peronal intubation biopsy in patients with malabsorption. In Proceedings of the World Congress of Gastroenterology, 1958, 1, 629-639. Williams and Wilkins, Baltimore.

Crosby, W. H., and Kugler, H. W. (1957). Intraluminal biopsy of the small intestine. The Intestinal biopsy capsule. Amer. J. dig. Dis., 2, 236-241.

Doniach, I., and Shiner, M. (1957). Duodenal and jejunal biopsies. II. Histology. Gastroenterology, 33, 71-86.

Fone, D. J., Meynell, M. J., Harris, E. L., Cooke, W. T., Brewer, D. B., and Cox, E. V. (1960). Jejunal biopsy an adult coeliac disease and allied disorders. Lancet, 1, 933-939.

Girdwood, R. H., Delamore, I. W., and Williams, A. W. (1961). Jejunal biopsy in malabsorptiove disorders of the adult. Brit. med. J., 1, 319-323.

Holmes, R., Hourihane, D. O'B., and Booth, C. C. (1961a). Dissecting -microscope appearances of jejunal biopsy specimens from patients with idiopathic steatorrhoea. Lancet, 1, 81-83.

- -1 (1961b). The mucosa of the small intestine. Postgrad. med. J., 37, 717-724.

Hourihane, D. O'B. (1963). The histolegy of intestinal biopsies. Proc. roy. Soc. Med., 56, 1073-1077.

Kamer, J. H., van de, Huinink, H. ten B., and Weyers, H. A. (1949). Rapid method for the determination of fat in feces. J. biol. Chem., 177, 347-355.

Klipstein, F. A. (1964). Tropical sprue in New York City. Gastroenterology, 47, 457-470.

Leblond, C. P., and Stevens, C. E. (1948). The constant renewal of the intestinal epithelium in albino rat. Anat. Rec., 100, 357-377.

Manson, P. (1879-80). Notes on sprue. China imp. Customs med. Rep., Shanghai, 19, 33-37.

Milanes, F., Leon, P., and Causa, A. (1951). Jejunum histopathological studies through surgical biopsy in a case of tropical sprue in relapse. Rev. Gastroent. (Mex.), 18, 182-192.

Mollin, D. L., (1962). In Intestinal Biopsy (Ciba Foundation Study Group No. 14), p. 100.

O'Brien, W., and England, N. W. J. (1964). Folate deficiency in acute tropical sprue. Brit. med. J., 2, 1573-1575.

Rubin, C. E., Brandborg, L. L., Phelps, P. C., and Taylor, H. C., Jr. (1960). Studies of celiac disease. I. The apparent identical and specific nature of the duodenal and proximal jejunal lesion in celiac disease and idiopathic sprue. Gastroenterology, 38, 28-49

Santiai, R. Jr., Sheehy, T. W., and Martinez-de Jesus, J. (1961). The xylose tolerance test with a five-gram dose. Ibid., 40, 772-774.

Sheehy, T. W., Baggs, B., Perez-Santiago, E., and Floch, M. H. (1962a). Prognosis of tropical sprue. A study of the effect of folic acid on the intestinal aspects of acute and chronic sprue. Ann. intern. Med., 57, 892-908.

- Cohen, W. H., and Brodsky, J. P. (1963). The intestinal lesion in the initial phase of tropical (military) sprue. Amer. J. dig. Dis., 8, 826-836.

- Perez-Santiago, E., and Floch, M. H. (1962b). The prognosis of tropical sprue. Ibid., 7, 960-961.

Shiner, M. (1956). Duodenal biopsy. Lancet, 1, 17-19.

and Doniach, I. (1959). Histopathologic studies in steatorrhea. In Proceedings of the World Congress of Gastroenterology, 1958 vol. 1, pp. 586-607. Williams and Wilkins, Baltimore.

Sprinz, H. (1962). Morphological response of intestinal mucosa to enteric bacteria and its implication for sprue and Asiatic cholera. Fed. Proc., 21, 57-64.

- Sribhibhadh, R., Gangarosa, E. J., Benyajati, C., Kundel, D., and Halstead, S. (1962). Biopsy of small bowel of Thai people. Amer. J. clin. Path., 38, 43-51.

Suárez, R. M., Spies, T. D., and Suárez, R. M., Jr. (1947). The use of folic acid in Sprue. Ann. intern. Med., 26, 643-677.

Swanson, V. L., and Thomasson, R. W. (1964). Pathology of the jejunal mucosa in tropical sprue. Amer. J. dig. Dis., 9, 772-774.

Thije, O. J. ten (1963). Intestinal mucosa and sprue. M.D. Thesis, University of Groningen.

Thurlbeck, W. M., Benson, J. A. Jr., and Dudley, H. R. Jr. (1960) The histopathologic changes of sprue and their significance. Amer. J. clin. Path., 34, 108-117. 